\title{
BERGERAK DAN BERKARYA BERSAMA SLB B-C CAHAYA JAYA, KELAPA GADING
}

\author{
Shanty Sudarji \\ Universitas Bunda Mulia \\ Email: gbu120711@gmail.com
}

\begin{abstract}
In Indonesia, education can be classified into formal, non-formal, and informal education. Special School (SLB) is one form of formal school that is devoted to provide educational services for students with special needs. Students and special needs students have significant differences in some important dimensions of their humanitarian function. This explains that physically, psychologically, cognitively, or socially obstructed in achieving its goals or needs and maximum potential, including those who are deaf, blind, have speech impairment, disability, mental retardation, emotional distress. Also gifted children with high intelligence. SLB B-C Cahaya Jaya provides special education for special needs students, including student with hearing impairment dan students with intellectual disabilities. This activity was given for 40 students with special needs which 11 students with hearing impairment and 29 students with intellectual disabilities. The activities are singing, playing balloons, pasting, painting, garnishing and dining. The objective is to refresh physical motor activity and learning to make a simple artwork with practical and fun means. The hoped benefits are to stimulate creativity, increase motorperception coordination and to train social abilities to interact with others. Students can follow the activities cooperatively, and they can finish them independently or with assistance. Overall of the process, the activities went well.
\end{abstract}

Keywords: hearing impairement, intellectual disability, perception-motor

\begin{abstract}
ABSTRAK: Di Indonesia, pendidikan dapat diklasifikasikan menjadi pendidikan formal, non formal, dan informal. Sekolah Luar Biasa (SLB) merupakan salah satu bentuk sekolah formal yang dikhususkan memberikan layanan pendidikan bagi siswa-siswi dengan kebutuhan khusus. Siswa dan siswi berkebutuhan khusus secara signifikan memiliki perbedaan dalam beberapa dimensi yang penting dari fungsi kemanusiaannya. Hal ini menjelaskan bahwa secara fisik, psikologis, kognitif, atau sosial terhambat dalam mencapai tujuan-tujuan atau kebutuhan dan potensinya secara maksimal, meliputi mereka yang tuli, buta, memiliki gangguan bicara, cacat tubuh, keterbelakangan mental, gangguan emosional. Juga anak-anak berbakat dengan inteligensi yang tinggi. SLB B-C Cahaya Jaya memberikan layanan pendidikan bagi siswa dan siswi tuna rungu wicara dan tuna grahita. Kegiatan diberikan bagi 40 orang siswa siswi berkebutuhan khusus dengan jumlah 11 orang siswa siswi tuna rungu dan 29 siswa siswi tuna grahita. Aktivitas yang diberikan antara lain bernyanyi dan bermain balon, menempel, melukis, menghias roti dan makan bersama. Tujuan dari kegiatan yang diberikan adalah untuk penyegaran berupa aktivitas fisik motorik dan belajar membuat suatu karya yang sederhana melalui cara-cara praktis yang menyenangkan. Manfaat yang diharapkan antara lain untuk merangsang daya kreativitas, meningkatkan koordinasi persepsi-motorik dan melatih kemampuan sosial untuk berinteraksi dengan orang lain. Siswa dan siswi dapat mengikuti kegiatan yang diberikan dengan kooperatif, mereka dapat menyelesaikan aktivitas yang diberikan baik secara mandiri maupun dengan pendampingan. Secara umum kegiatan berjalan dengan baik.
\end{abstract}

Kata Kunci: tuna rungu, tuna grahita, persepsi-motorik

\section{PENDAHULUAN}

\section{A. Latar belakang}

Pendidikan di Indonesia terdiri dari pendidikan formal, non formal, dan informal. Sekolah Luar Biasa (SLB) merupakan salah satu bentuk sekolah formal yang dikhususkan memberikan layanan pendidikan bagi siswa- siswi dengan kebutuhan khusus. Siswa dan siswi berkebutuhan khusus adalah mereka yang secara signifikan berbeda dalam beberapa dimensi yang penting dari fungsi kemanusiaannya. Mereka yang secara fisik, psikologis, kognitif, atau sosial terhambat dalam mencapai tujuan-tujuan atau kebutuhan 
dan potensinya secara maksimal, meliputi mereka yang tuli, buta, memiliki gangguan bicara, cacat tubuh, keterbelakangan mental, gangguan emosional. Juga anak-anak berbakat dengan inteligensi yang tinggi, dapat dikategorikan sebagai individu berkebutuhan khusus atau luar biasa, karena memerlukan penanganan yang terlatih dari tenaga profesional (Suram \& Rizzo, dalam Mangunsong, 2009).

Gearheart (dalam Mangunsong, 2009) mengemukakan bahwa seorang individu dianggap berkebutuhan khusus bila memerlukan persyaratan pendidikan yang berbeda dari rata-rata anak normal, dan untuk dapat belajar secara efektif memerlukan program, pelayanan, fasilitas dan materi khusus. SLB B-C Cahaya Jaya yang berlokasi di Kelapa Gading, Jakarta Utara adalah sekolah luar biasa yang memberikan layanan pendidikan bagi siswa dengan tuna rungu dan tuna grahita.

\section{B. Identifikasi masalah}

Proses pembelajaran memerlukan optimalisasi keterlibatan seluruh aspek yang dimiliki siswa dalam kegiatan pembelajaran di sekolah menuntut para pendidik untuk terus mengembangkan model, metode, media, bahkan strategi pembelajaran yang berorientasi pada keaktifan siswa (student centered learning) (Cahyani \& Huda, 2016).

Siswa dan siswi yang bersekolah di SLB B-C Cahaya Jaya membayar uang sekolah secara sukarela. Jumlah siswa siswi tuna rungu dan tuna grahita sebanyak kurang lebih 40 orang dirasakan belum sebanding dengan jumlah guru yang menangani mereka. Guru seringkali tidak dapat menangani semua siswa dan siswi secara optimal, sehingga mereka sangat terbuka terhadap masyarakat luas khususnya institusi yang juga bergerak dalam bidang pendidikan untuk membantu memberikan aktivitas bagi siswa. Siswa dan siswi berkebutuhan khusus di SLB B-C Cahaya Jaya juga menyukai ragam kegiatan yang melibatkan aktivitas fisik motorik. Dengan adanya sambutan dan dukungan dari para guru, maka mahasiswa program studi Psikologi dari Universitas Bunda Mulia merancang kegiatan yang melibatkan aktivitas motorik halus dan motorik kasar bagi para siswa dan siswi tuna rungu dan tuna grahita di SLB B-C Cahaya Jaya.

\section{Tujuan dan manfaat kegiatan}

Tujuan dari kegiatan yang bertema "Bergerak dan Berkarya Bersama" antara lain untuk memberikan penyegaran berupa aktivitas fisik motorik dan belajar membuat suatu karya yang sederhana melalui cara-cara praktis yang menyenangkan.

Manfaat yang diharapkan melalui kegiatan yang diberikan bagi siswa siswi berkebutuhan khusus di SLB B-C Cahaya Jaya antara lain untuk merangsang daya kreativitas, meningkatkan koordinasi persepsi-motorik dan melatih kemampuan sosial untuk berinteraksi dengan orang lain. Latihan koordinasi persepsimotorik dalam jangka panjang dapat membantu siswa siswi dalam meningkatkan kemampuan membaca dan menulis, dimana kedua kemampuan dasar ini lebih sulit diajarkan kepada mereka yang berkebutuhan khusus dibandingkan siswa siswi yang normal.

\section{TINJAUAN PUSTAKA}

\section{A. Siswa berkebutuhan khusus}

Berdasarkan sudut pandang pendidikan, Hallahan dan Kauffman (2006) mengemukakan pengertian siswa berkebutuhan khusus adalah mereka yang memerlukan pendidikan khusus dan pelayanan terkait, pendidikan khusus diperlukan karena mereka tampak berbeda dari siswa pada umumnya dalam satu atau lebih hal berikut: mereka mungkin memiliki keterbelakangan mental, ketidakmampuan belajar atau gangguan atensi, gangguan emosi atau perilaku, hambatan fisik, hambatan bahasa dan komunikasi, autisme, traumatic brain injury, hambatan pendengaran, hambatan penglihatan, dan anak-anak dengan inteligensi sangat tinggi ( gifted/talented).

Kekhususan yang relevan dari perbedaan cara belajar, membutuhkan instruksi yang berbeda dari yang umum diperlukan para siswa. Kekhususan mereka dapat mencakup bidang sensori, fisik, kognitif, emosi, atau kemampuan komunikasi ataupun kombinasinya. Kekhususan dapat sangat berbeda dalam hal penyebab, tingkat keparahan, dampak bagi kemajuan pendidikan, dan dampak ini dapat tergantung dari usia, jenis kelamin, dan lingkungan hidupnya (Mangunsong, 2009).

Dalam hal kecepatan belajar, anak dengan kebutuhan khusus terutama yang mengalami keterbelakangan mental akan jauh tertinggal jika dibandingkan anak normal. Pemberian instruksi harus diberikan sederhana dan sejelas mungkin, hal ini dikarenakan sel 
kortikal anak dengan keterbelakangan mental lebih lambat dalam perubahan kimia, listrik, dan perubahan fisik sehingga fleksibilitas mental yang kurang dapat mengakibatkan kesulitan dalam pengorganisasian materi yang akan dipelajari, oleh karena itu sulit bagi mereka untuk menangkap informasi yang kompleks (Somantri, dalam Sudarji, 2011).

Salah satu pendekatan yang dapat digunakan untuk mengajar siswa dengan kebutuhan khusus tahap ringan, telah dipusatkan kepada masalah-masalah perseptual yang mereka hadapi yakni keterampilan motorik kasar, keterampilan motorik halus, persepsi bentuk, pengurutan ingatan, perbedaan visual dan auditif. Latihan perseptual tidak hanya memperingan masalah-masalah terkait perseptual dan akademik, namun juga defisit perilaku terutama kurangnya perhatian (Mangunsong, 2009).

\section{B. Sekolah luar biasa}

Sekolah khusus untuk anak berkebutuhan khusus, biasanya ditujukan untuk kategori kebutuhan khusus dengan materi dan peralatan yang sesuai untuk pengasuhan dan pendidikan mereka. Siswa siswi ini biasanya pulang ke rumah setelah program sekolah usai. Di Indonesia, dikenal SLB A untuk tuna netra, SLB B untuk tuna rungu, SLB C untuk tuna grahita, SLB D untuk tuna daksa, dan SLB E untuk tuna laras (disruptive). Bahkan dalam kebijakan dan program direktorat pembinaan SLB (2006), disebutkan jenis anak berkebutuhan khusus lainnya yaitu: $\mathrm{F}$ untuk tuna wicara, $\mathrm{G}$ untuk tuna ganda, $\mathrm{H}$ untuk HIV AIDS, I untuk gifted (dengan potensi kecerdasan istimewa), J untuk talented (dengan potensi bakat istimewa atau multiple inteligences), $\mathrm{K}$ untuk kesulitan belajar, $\mathrm{L}$ untuk lambat belajar, $\mathrm{M}$ untuk autisme, $\mathrm{N}$ untuk korban penyalahgunaan narkoba, dan $\mathrm{O}$ untuk indigo (Mangunsong, 2009).

SLB B-C Cahaya Jaya didirikan oleh swasta pada tahun 1985, hingga saat ini berlokasi di daerah Kelapa Gading, Jakarta Utara, menangani siswa siswi dengan tuna rungu wicara dan tuna grahita, dan terdapat beberapa siswa dengan autisme. Guru tetap berjumlah lima orang, dibantu oleh satu orang psikolog yang datang paruh waktu. Juga terdapat beberapa mahasiswa magang dari berbagai perguruan tinggi di Jabodetabek.

\section{Aktivitas bermain bagi siswa}

Keterampilan kejuruan lebih diutamakan untuk diberikan kepada siswa dan siswi berkebutuhan khusus seperti tuna rungu dan tuna grahita (Ormrod, 2008). Aktivitas belajar akan lebih mudah mereka ikuti jika diberikan dengan cara-cara yang menyenangkan, dengan menekankan kepada proses daripada hasil. Aktivitas belajar sembari bermain memiliki manfaat antara lain untuk merangsang fungsi panca indera, meningkatkan ketangkasan, meningkatkan kemampuan berbicara dan berbahasa, serta meningkatkan interaksi sosial dengan orang lain (Bilantira, 2016).

\section{Latihan Kreativitas}

Pengembangan daya cipta atau kreativitas bertujuan membuat anak-anak kreatif, yakni lancar, fleksibel dan orisinil dalam bertutur kata, berpikir, serta berolah tangan, berolah seni dan berolah tubuh sebagai latihan motorik halus dan motorik kasar. Munandar (dalam Devi, 2014) mengemukakan bahwa ada empat alasan utama perlunya pengembangan kreativitas sejak usia dini yaitu: (1) Kreativitas untuk merealisasikan perwujudan diri, (2) Kreativitas untuk memecahkan suatu permasalahan; kreativitas atau berfikir kreatif merupakan kemampuan untuk melihat berbagai kemungkinan penyelesaian terhadap suatu permasalahan, (3) Kreativitas untuk memuaskan diri, (4) Kreativitas untuk meningkatkan kualitas hidup; individu yang kreatif akan mempunyai banyak ide yang dapat dikembangkan sehingga memiliki kemungkinan untuk memperoleh kesejahteraan yang lebih baik dibandingkan orang yang tidak kreatif. Untuk mencapai hal itu perlu sikap, pemikiran, dan perilaku kreatif yang dipupuk sejak dini.

Sumanto (dalam Devi, 2014) mengemukakan keragaman bentuk kegiatan berkarya kreatif berkaitan langsung dengan digunakannya jenis media (bahan praktek) yang disesuaikan dengan teknik pembuatannya. Alat dan bahan yang sudah ditentukan, menggunakan alat bidang dasaran berupa kertas hvs, kertas gambar, lem kayu, lem kertas, gunting dan pensil, serta menggunakan bahan alam, dan bahan kertas. Kegiatan menempel sesuai pola (mozaik) dan menghias roti menggunakan selai bagi siswa siswi berkebutuhan khusus dapat membantu mereka mengembangkan imajinasi dan melatih daya cipta atau kreativitas. 


\section{METODE}

Metode yang digunakan berupa pemberian aktivitas fisik seperti bermain, bernyanyi, menempel kertas, dan menghias roti menggunakan selai cokelat dan keju. Aktitas yang diberikan dirancang sesuai kebutuhan siswa siswi berkebutuhan khusus di SLB B-C Cahaya Jaya. Pemberian instruksi dilakukan secara sederhana, dengan bahasa yang dapat dipahami oleh siswa siswi, durasi waktu juga dipertimbangkan untuk dilaksanakan dengan waktu sesingkat mungkin mengingat renatng perhatian yang dimiliki siswa dan siswi tergolong pendek.

Kegiatan bermain dan bernyanyi dilaksanakan selama kurang lebih 45 menit, menempel gambar dan melukis sendok plastik dilaksanakan selama 45 menit, menghias roti dan makan bersama dilaksanakan dalam waktu 45 menit. Pemberian aktivitas dilaksanakan oleh dosen dan 17 orang mahasiswa program studi Psikologi Universitas Bunda Mulia.

Tabel 1. Rancangan Kegiatan

\begin{tabular}{|c|c|c|c|}
\hline Waktu & Kegiatan & Peralatan & Tujuan \\
\hline $08.15-09.00$ & $\begin{array}{l}\text { Bermain dan } \\
\text { bernyanyi }\end{array}$ & Balon aneka warna & $\begin{array}{l}\text { Melatih koordinasi motorik } \\
\text { kasar dan meningkatkan } \\
\text { atensi serta kemampuan } \\
\text { sosial (berinteraksi dengan } \\
\text { orang lain) melalui gerak } \\
\text { dan lagu }\end{array}$ \\
\hline $09.00-09.20$ & Menempel gambar & $\begin{array}{l}\text { Kertas hvs bergambar, } \\
\text { kertas hvs kosong, } \\
\text { kertas origami } \\
\text { beraneka warna, lem } \\
\text { kertas }\end{array}$ & $\begin{array}{l}\text { Melatih koordinasi motorik } \\
\text { halus dan motorik kasar, } \\
\text { serta merangsang daya cipta } \\
\text { atau kreativitas dan juga } \\
\text { untuk meningkatkan } \\
\text { kemampuan atensi }\end{array}$ \\
\hline $\begin{array}{l}09.20- \\
09.45\end{array}$ & $\begin{array}{l}\text { Melukis sendok } \\
\text { plastik }\end{array}$ & $\begin{array}{l}\text { Sendok plastik, pulpen, } \\
\text { spidol, stabilo, krayon, } \\
\text { kertas origami, karton } \\
\text { bufalo, kertas krepe, } \\
\text { benang wool, lem } \\
\text { plastik }\end{array}$ & $\begin{array}{l}\text { Melatih koordinasi motorik } \\
\text { kasar, dan merangsang daya } \\
\text { cipta atau kreativitas }\end{array}$ \\
\hline $09.45-10.30$ & $\begin{array}{l}\text { Melukis roti dan } \\
\text { makan bersama }\end{array}$ & $\begin{array}{l}\text { Roti tawar, selai } \\
\text { cokelat, selai keju, } \\
\text { sendok plastik untuk } \\
\text { selai }\end{array}$ & $\begin{array}{l}\text { Melatih koordinasi motorik, } \\
\text { merangsang daya cipta atau } \\
\text { kreativitas, dan melatih } \\
\text { kemampuan sosial (interaksi } \\
\text { dengan lingkungan sekitar) }\end{array}$ \\
\hline $10.30-10.45$ & Evaluasi kegiatan & $\begin{array}{l}\text { Kertas evaluasi untuk } \\
\text { guru }\end{array}$ & $\begin{array}{l}\text { Mengukur efektivitas } \\
\text { kegiatan yang telah } \\
\text { diberikan bagi siswa siswi } \\
\text { berkebutuhan khusus }\end{array}$ \\
\hline
\end{tabular}

Sumber: Data Primer

\section{HASIL DAN PEMBAHASAN}

\section{A. Bermain dan bernyanyi}

Dalam kegiatan ini siswa dan siswi gabungan dari tuna rungu sebanyak 11 orang siswa dan tuna grahita sejumlah 29 orang dibagi menjadi lima kelompok yang masingmasing terdiri dari delapan orang. Satu kelompok didampingi oleh tiga orang mahasiswa. Dua orang mahasiswa menginstruksikan kegiatan bernyanyi dan bermain di depan untuk selanjutnya diikuti oleh lima kelompok peserta yang telah dibagi.

Lagu-lagu yang dinyanyikan sembari bermain diantara adalah lagu "disini senang", "balonku", dan "sayonara". Siswa siswi bernyanyi sembari mengikuti gerakan yang diperagakan oleh pendamping. Terkadang, mereka membuat gerakan sendiri sesuai dengan irama dan lirik lagu. Mereka tampak antusias dan senang dalam mengikuti 
kegiatan ini. Beberapa siswa harus dibantu dalam menyanyikan lirik lagu dan bergerak sesuai contoh dikarenakan mereka tampak pasif dan belum lancar dalam berbahasa dan berkomunikasi. Koordinasi motorik juga masih perlu dilatih untuk mengikuti gerakan yang sederhana.

Sembari bernyanyi, juga dilakukan permainan melempar dan menangkap balon, kegiatan ini dilakukan di lapangan terbuka. Aktivitas ini bertujuan untuk merangsang koordinasi motorik dan ketangkasan siswa.
Dalam satu kelompok besar, diberikan dua buah balon untuk dilempar dan ditangkap secara bergiliran. Para siswa tampak antusias dalam mengikuti kegiatan, beberapa siswa membutuhkan bantuan dan diperlukan contoh berulang untuk dapat melakukan permainan sesuai instruksi dan aturan yang ditetapkan. Mereka tampak senang bermain dengan balon beraneka warna yang disediakan oleh panitia acara.

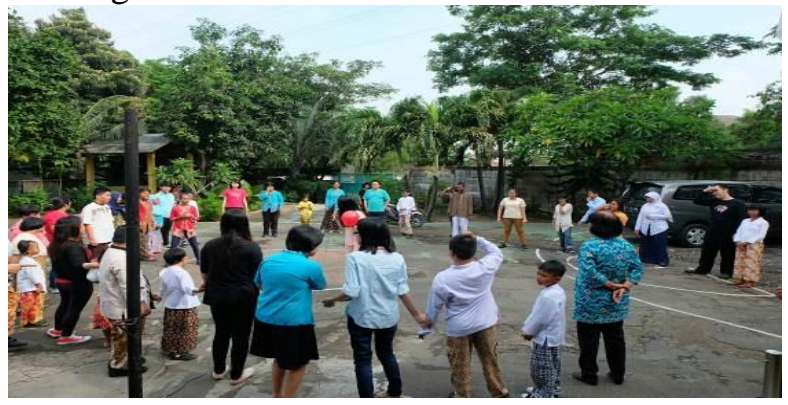

Gambar 1. Lempar Tangkap Balon Sumber: Data Primer

Kegiatan yang direncanakan berlangsung selama 45 menit dapat berjalan dengan baik dan sesuai rencana. Para guru juga berkenan untuk turut serta membantu jalannya aktivitas yang diberikan bagi para peserta didik, terutama untuk siswa siswi tuna rungu yang memerlukan instruksi yang lebih khusus dibandingkan siswa siswi dengan tuna grahita.

\section{B. Menempel gambar dan melukis sendok}

Kegiatan menempel gambar dan melukis sendok masih diikuti oleh kelompok yang sama seperti dalam kegiatan bermain dan benyanyi, hanya saja terdapat beberapa siswa tuna rungu yang tidak lagi berpartisipasi dalam kegiatan ini.

Setiap kelompok yang terdiri dari enam sampai delapan siswa diberikan sebuah kertas hvs dengan gambar bertitik-titik untuk disambungkan menjadi suatu gambar yang bermakna seperti gambar binatang, buah, ataupun gambar sederhana, yang harus dikerjakan oleh para siswa antara lain menelusur titik-titik, setelah selesai diminta mengenali gambar apa yang mereka buat, kemudian menyobek kertas origami menjadi potongan kecil-kecil untuk selanjutnya ditempel ke gambar tersebut menggunakan lem kertas. Kegiatan menempel gambar ini bertujuan melatih koordinasi persepsi motorik siswa dan juga untuk meningkatkan kemampuan atensi siswa. Beberapa siswa harus dibantu untuk menyobek kertas origami menjadi potongan-potongan kecil, sementara beberapa siswa lainnya tampak cukup dapat melakukan kegiatan secara mandiri, dengan bantuan seminimal mungkin dari para pendampingnya. Dalam kegiatan ini para pendamping juga harus lebih memperhatikan perilaku siswa karena terdapat kemungkinan siswa menjilat lem kertas yang diberikan, ataupun merobek-robek kertas gambar yang telah diberikan. Bagi siswa yang mampu menulis, dapat menuliskan namanya sendiri dan kelasnya di kertas yang telah diberikan. Para siswa tampak kooperatif dalam mengikuti kegiatan.

Dalam kegiatan melukis sendok, setiap siswa siswi diberikan satu buah sendik plastik, kemudian dilukis dengan menggunakan pilihan alat seperti spidol, stabilo, krayon, kertas origami, kertas krepe, benang wool ukuran tebal, dan karton bufalo serta lem. Sebelum kegiatan dilaksanakan, para pendamping memberikan contoh terlebih dahulu bagaimana mengerjakan aktivitas tersebut secara bertahap. Alat yang paling banyak dipilih oleh para siswa untuk menghias adalah kertas krepe dan benang wool berukuran tebal. Dalam kegiatan ini, banyak siswa yang harus dibantu secara fisik 
oleh para pendamping. Para siswa tampak tertarik dalam melakukan kegiatan ini, namun beberapa tampak menyerah dan tidak melanjutkan aktivitas sampai akhir.

\section{Menghias roti dan makan bersama}

Kegiatan selanjutnya adalah menghias roti tawar. Alat yang disediakan antara lain roti tawar, selai cokelat dan selai keju, juga sendok.

Kegiatan menghias roti juga dilaksanakan secara berkelompok. Dalam aktivitas ini, beberapa siswa tidak berpartisipasi. Sebelum kegiatan dilaksanakan, para pendamping memberikan contoh, mendemonstrasikan bagaimana cara mengoleskan selai ke roti yang akan dihias. Para siswa tampak antusias dalam melakukan kegiatan ini.

Kegiatan menghias roti berlangsung selama kurang lebih dua puluh menit, selanjutnya diikuti dengan acara makan roti bersama antara siswa siswi dengan para pendamping dan juga guru. Kegiatan makan bersama berlangsung lebih lama daripada kegiatan menghias roti, karena setiap siswa makan dengan kecepatan yang sangat bervariasi, ada yang makan dengan cepat dan ada pula yang makan dengan sangat lambat, juga terdapat beberapa siswa dan siswi tuna grahita yang harus dibantu untuk makan dengan baik dan benar. Sebelum dan sesudah makan, siswa siswi juga diingatkan dan diarahkan untuk membersihkan tangan.

\section{Evaluasi kegiatan}

Secara umum, kegiatan dapat terlaksana sesuai dengan rancangan kegiatan yang telah disusun oleh panitia. Kegiatan berlangsung sesuai waktu yang telah ditetapkan. Para siswa dan siswi tampak sudah disiapkan oleh para guru untuk mengikuti kegiatan yang akan dilaksanakan oleh dosen dan para mahasiswa dari Universitas Bunda Mulia.

Dalam setiap kegiatan, secara umum siswa dan siswi dapat mengikuti kegiatan dengan kooperatif, mereka dapat diarahkan oleh para pendamping. Meskipun demikian, terdapat beberapa siswa yang memerlukan pendampingan khusus selama kegiatan berlangsung. Mereka harus diberikan pendampingan secara individual untuk dapat mengikuti kegiatan dari awal hingga akhir.
Kesulitan terbesar yang dialami adalah saat pemberian instruksi terutama instruksi yang diberikan bagi siswa dan siswi tuna rungu. Setiap instruksi yang diberikan oleh panitia, harus dibantu untuk disampaikan kembali oleh guru agar dapat dipahami oleh siswa dan siswi tuna rungu. Demikian juga dengan siswa tuna grahita tahap sedang dan berat. Penyampaian instruksi yang dirasakan sudah sangat sederhana, harus seringkali diberikan berulang agar semakin dipahami oleh para siswa dan siswi berkebutuhan khusus tersebut. Selain itu, panitia juga harus selalu peka terhadap kondisi setiap siswa, karena beberapa siswa mengalami tantrum dan tidak dapat mengikuti aktivitas sampai akhir, hal ini antara lain dapat disebabkan karena rasa bosan dalam mengikuti aktivitas, ataupun karena tidak mampu melakukan aktivitas yang diberikan sehingga muncul rasa frustasi yang berujung pada tantrum.

Berdasarkan evaluasi yang diberikan oleh para guru, didapati bahwa secara keseluruhan, acara berlangsung dengan baik, para siswa dan siswi sangat senang dan mau turut berpartisipasi mengikuti seluruh rangkaian aktivitas yang diberikan. Pemberian kegiatan disarankan oleg guru agar lebih sederhana dan disesuaikan kembali dengan kebutuhan setiap siswa agar hasil yang diperoleh lebih maksimal. Penggunaan bahasa dan komunikasi yang digunakan sudah cukup baik, meskipun harus diberikan secara berulang agar lebih dipahami oleh para siswa. 


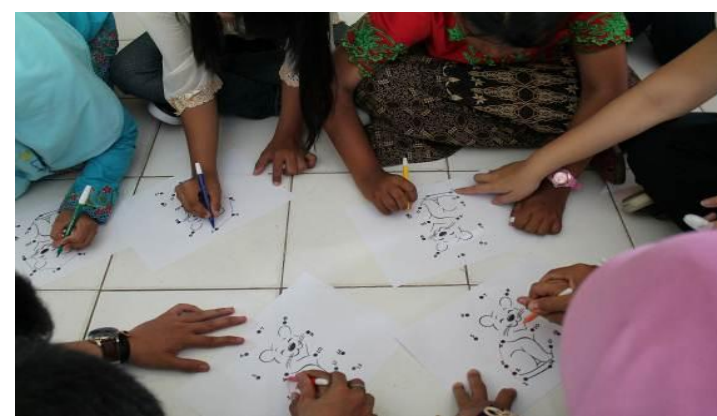

Gambar 2. Menelusur Garis Untuk Disambungkan Menjadi Suatu Bentuk Yang Bermakna Sumber: Data Primer

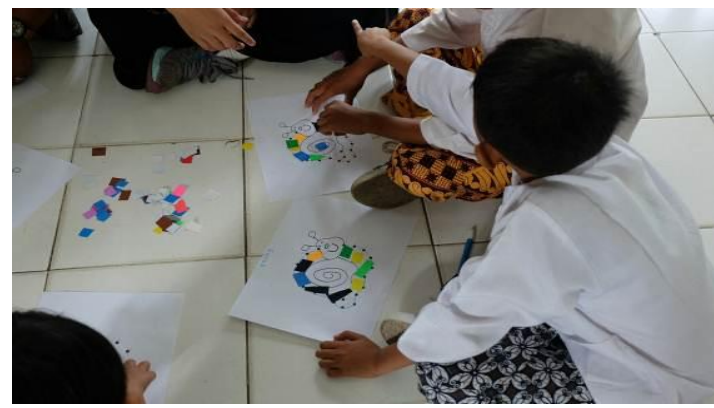

Gambar 3. Menempel Gambar Dengan Kertas Origami Sumber: Data Primer

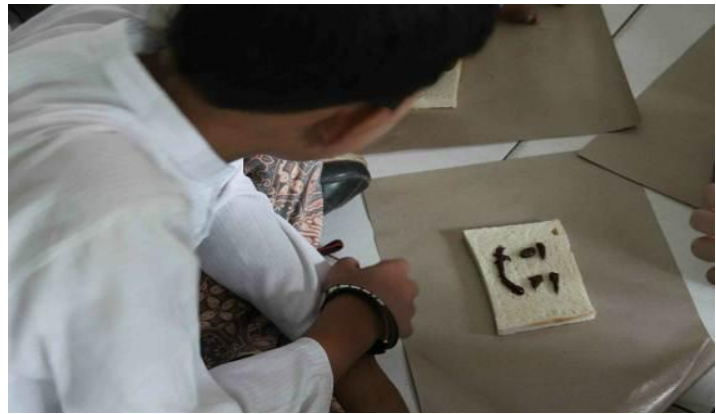

Gambar 4. Menghias Roti

Sumber: Data Primer

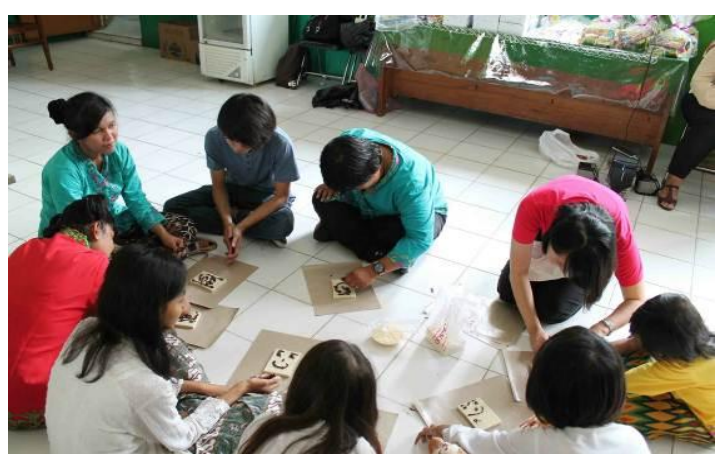

Gambar 5. Menghias Roti Dan Makan Bersama Sumber: Data Primer 


\section{SIMPULAN DAN SARAN \\ Simpulan}

Secara umum, dapat disimpilkan bahwa kegiatan yang telah dilaksanakan dengan tema "Bergerak dan Berkayra Bersama" di SLB B-C Cahaya Jaya berjalan dengan lancar. Aktivitas yang diberikan lebih banyak mengarah kepada kegiatan motorik kasar, dengan tujuan meningkatkan atensi, koordinasi persepsi-motorik, dan juga untuk melatih keterampilan sosial siswa. Manfaat ini secara jangka pendek dapat dilihat selama proses kegiatan berlangsung. Setiap siswa dapat melakukan kegiatan yang diberikan, baik secara mandiri maupun dengan pendampingan.

\section{Saran}

\begin{abstract}
Kegiatan yang telah dilaksanakan dirasakan masih memiliki banyak kekurangan. Untuk itu, disarankan bagi kegiatan selanjutnya agar lebih mempertimbangkan kondisi setiap siswa dan juga dapat mengantisipasi masalah yang mungkin muncul seperti tantrum yang dialami oleh siswa. Satu orang siswa tantrum dapat mempengaruhi kondisi siswa lainnya, sehingga sedikit banyak juga berpengaruh terhadap jalannya aktivitas yang sedang berlangsung. Selain itu, disarankan juga memberikan aktivitas yang lebih sederhana dan bervariasi dengan memperhitungkan durasi waktu agar siswa tidak cepat bosan dan berpengaruh terhadap kestabilan emosi mereka. Aktivitas yang melibatkan gerakan fisik aktif seperti bernyanyi dan bergerak mengikuti irama lebih disukai oleh para siswa berkebutuhan khusus di SLB B-C Cahaya Jaya dibandingkan kegiatan yang lebih pasif seperti menempel dan melukis.
\end{abstract}

\section{DAFTAR PUSTAKA}

Bilantira., 2016. Manfaat bermain bagi anak usia dini. Jakarta: Kemang Medical Care, Women \& Children.

Cahyani, E.N., Huda. A., 2016. The effect of the scales media toward mastery of the weight measuring concept for students with intellectual disbility (Pengaruh penggunaan media timbangan terhadap penguasaan konsep

pengukuran berat pada siswa tunagrahita). Skripsi Universitas Negeri Malang.

Devi, F.P., 2014. Peningkatan kreativitas melalui kegiatan kolase pada anak kelompok B2 di TK ADA Keringan Kecamatan turi Kabupaten Sleman. Skripsi Pendidikan Guru Pendidikan Anak Usia Dini Jurusan Pendidikan Pra Sekolah dan Sekolah Dasar Fakultas Ilmu Pendidikan Universitas Negeri Yogyakarta, h. 15.

Ormrod, J. E., 2008. Psikologi pendidikan, membantu siswa tumbuh dan berkembang. Jakarta: Penerbit Erlangga

Sudarji, S., 2011. Peranan remedial teaching dalam meningkatkan kemampuan membaca pada anak dengan mild intellectual disability. Tesis Program Studi Magister Psikologi Fakultas Psikologi Universitas Tarumanagara Jakarta, h. 26-27 